\title{
Correction to Algorithm 39 \\ Clusterwise Linear Regression
}

\author{
H. Späth, Oldenburg
}

[Computing 22, 367-373 (1979)]

The algorithm printed on pp. $369-370$ is not a correct implementation of the proposed method although it will normally also yield acceptable results to the stated problem. E. g., in the case of the numerical example presented it generates the same solution as the correct algorithm; see table 2 .

The following replacements lead to a correct implementation of the proposed method:

a) Replace the statement with label 8 by the two statements

$8 \mathrm{FF}=\mathrm{FF}-\mathrm{E}(\mathrm{J})$

$$
\text { IF (FF. GT.BF) GOTO } 10
$$

b) Replace the statement with label 11 by

$11 \mathrm{BU}=\mathrm{BF}$

c) Replace the second statement after the one with label 12 by

$$
\mathrm{E}(\mathrm{U})=\mathrm{E}(\mathrm{U})+\mathrm{BU}
$$

(Remark: As a lot of people were interested in that algorithm the author is currently developing a much faster implementation.)

Prof. Dr. H. Späth

Fachbereich IV

Universität Oldenburg

Postfach 2503

D-2900 Oldenburg

Federal Republic of Germany

$$
0010-485 X / 81 / 0026 / 0275 / \$ 01.00
$$

Eigentümer, Herausgeber und Verleger: Springer-Verlag. A-1011 Wien, Mölkerbastei 5. - Für den Textteil verantwortlich: Dr. Wilhelm Schwabl, A-1011 Wien, Mölkerbastei 5. - Für den Anzeigenteil verantwortlich: Mag. Bruno Schweder, A-1011 Wien, Mölkerbastei 5. - Satz: Austro-Filmsatz Richard Gerin, A-1020 Wien, Fischergasse 1. Druck: Paul Gerin, A-1021 Wien, Zirkusgasse 13. 